\title{
PRODUÇÃO DE ISOMALTULOSE, UM SUBSTITUTO DA SACAROSE, UTILIZANDO GLICOSILTRANSFERASE MICROBIANA
}

\author{
Haroldo Yukio Kawaguti* e Hélia Harumi Sato \\ Departamento de Ciência de Alimentos, Faculdade de Engenharia de Alimentos, Universidade Estadual de Campinas, \\ CP 6121, 13083-862 Campinas - SP, Brasil
}

Recebido em 11/10/06; aceito em 4/5/07; publicado na web em 19/12/07

\begin{abstract}
ISOMALTULOSE PRODUCTION, A NEW SUCROSE SUBSTITUTE, USING MICROBIAL GLUCOSYLTRANSFERASE. Isomaltulose, a functional isomer of sucrose, is a non-cariogenic reducing disaccharide; has a low glycemic index; selectively promotes growth of beneficial bifidobacteria in the human intestinal microflora; and has greater stability than sucrose in some foods and beverages. Isomaltulose is a nutritional sugar that is digested more slowly than sucrose, and has health advantages for diabetics and nondiabetics. Immobilization techniques, especially entrapment of the cells, are widely used for conversion of sucrose into isomaltulose. Immobilization offers advantages such as minimum downstream processing, continuous operation and reusability of cells. Isomaltulose is currently considered to be a promising sugar substitute.
\end{abstract}

Keywords: glucosyltransferase; isomaltulose; immobilized cells.

\section{INTRODUÇÃO}

A indústria de alimentos está constantemente à procura de novos ingredientes para melhorar os produtos existentes ou para introduzir novos produtos no mercado. A sacarose é o adoçante mais utilizado na produção de alimentos devido às suas características físico-químicas e sensoriais. No entanto, devido ao alto valor calórico e às propriedades cariogênicas da sacarose, adoçantes alternativos têm sido pesquisados. O Brasil é o maior produtor mundial de sacarose, com uma produção estimada em 29,2 milhões de t para a safra $2006 / 07^{1}$ e diversos produtos de interesse industrial podem ser obtidos a partir da sacarose como, por exemplo, açúcar invertido, dissacarídeos (isomaltulose e trealulose), frutooligossacarídeos, polissacarídeos (goma xantana e dextrana), etanol, ácido glutâmico, ácido cítrico etc.

Nas últimas duas décadas houve um crescente aumento no interesse da produção de isomaltulose, também conhecida como Palatinose $^{\circledR}$ ou Lylose ${ }^{\circledR}$, de ocorrência natural no mel e na cana-deaçúcar em pequenas quantidades, e tem sido considerada um promissor substituto da sacarose. A isomaltulose é um dissacarídeo redutor, isômero da sacarose, obtida por conversão enzimática microbiana a partir da sacarose $\mathrm{e}^{2,3}$. Pesquisas envolvendo a produção de isomaltulose iniciaram-se no Japão entre $1970-75^{4}$. A isomaltulose possui um sabor adocicado suave, apresentando cerca de $50 \%$ da doçura da sacarose ${ }^{5-9}$, tem propriedades físico-químicas e sensoriais muito similares e, quando utilizada em alimentos, como substituto da sacarose em confeitos e chocolates, não foi notada diferença na doçura ${ }^{9-11}$.

A isomaltulose possui baixo potencial cariogênico, sendo utilizada comercialmente no Japão como ingrediente e substituinte da sacarose na produção de gomas de mascar, iogurtes, doces e bebidas ${ }^{9}$. Apresenta também baixa velocidade de hidrólise e formação de monossacarídeos no organismo, sendo recomendada para aplicação em alimentos e bebidas destinados a diabéticos e esportistas $^{3}$. A produção mundial de isomaltulose foi estimada em 60.000 $\mathrm{t}^{\mathrm{ano}} \mathrm{s}^{12}$.

\footnotetext{
*e-mail: kawaguti@fea.unicamp.br
}

O principal derivado da isomaltulose é o isomalte, um açúcarálcool obtido por hidrogenação com a formação de uma mistura equimolar de [6- $O$-( $\alpha$-D-glicopiranosil)-D-sorbitol] e [6- $O-(\alpha-\mathrm{D}$ glicopiranosil)-D-manitol], de baixo valor calórico e não cariogênico. $\mathrm{O}$ isomalte, também conhecido como Isomalt ${ }^{\circledR}$ e Palatinit ${ }^{\circledR}$, tem atraído a atenção de pesquisadores devido a sua aplicação industrial como substituto da sacarose em processamento de alimentos, sendo utilizado como adoçante dietético, não cariogênico e em formulações farmacêuticas ${ }^{13-15}$. Muitos produtos derivados da isomaltulose possuem potenciais aplicações industriais. Podem ser obtidos dissacarídeos intermediários, polímeros como detergentes biodegradáveis e surfactantes de interesse industrial ${ }^{12,16}$. Uma outra aplicação da isomaltulose consiste na obtenção de oligômeros de isomaltulose, que atuam como prebióticos, estimulando a proliferação de bifidobactérias da microbiota intestinal ${ }^{17}$.

\section{CONVERSÃO DE SACAROSE EM ISOMALTULOSE POR VIA MICROBIANA}

A conversão de sacarose em isomaltulose por via microbiana tem atraído grande interesse comercial, pois a síntese química é muito difícil. A isomaltulose [ $\alpha$-D-glicopiranosil-(1,6)- $\beta$-D-frutofuranose] é obtida através da conversão enzimática da sacarose [1-O- $(\beta-\mathrm{D}-$ frutofuranosil)- $\alpha$-D-glicopiranose], pela $\alpha$-glicosiltransferase, também conhecida como sacarose isomerase e isomaltulose sintase (EC 5.4.99.11), na qual a ligação 1,2-glicosídica entre a glicose e a frutose é rearranjada para ligação 1,6-glicosídica (Esquema 1).

A enzima é produzida por diversos microrganismos como Protaminobacter rubrum ${ }^{7,18-20}$, Erwinia carotovora ${ }^{21}$, Erwinia sp. D12 ${ }^{22-24}$, Erwinia rhapontici ${ }^{10,25}$, Serratia plymuthica ${ }^{3,26,27}$, Klebsiella planticola $^{9}$ e Klebsiella $\mathrm{sp}^{28,29}$. O uso de microrganismos como biocatalisadores para obtenção de determinadas substâncias tem suas vantagens, como a alta capacidade de multiplicação e alta flexibilidade de utilização, graças ao seu poder de adaptação às várias situações nutricionais, modificando seu metabolismo de acordo com a oferta de nutrientes do meio ${ }^{30}$. Entre os sistemas de produção de isomaltulose, existem os de enzima livre $21,26,28,29$, células livres ${ }^{31-33}$ e células imobilizadas $3,5,8,10,18,20,23-25,30,34-36$. 


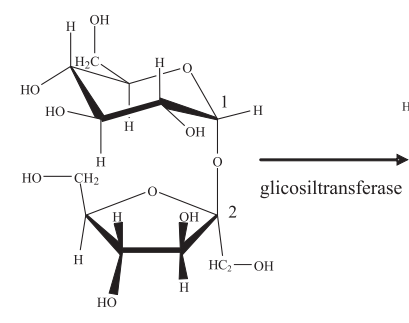

Sacarose

$\alpha$-D-glicopiranosil-(1 $\rightarrow 2)-\beta$-D-frutofuranose

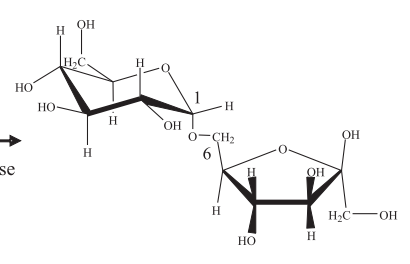

Isomaltulose

$O$ - $\alpha$-D-glicopiranosil-( $(1 \rightarrow 6)-\beta$-D-frutofuranose

Esquema 1. Conversão de sacarose em isomaltulose por glicosiltransferase microbiana

\section{Microrganismos produtores de glicosiltransferase que convertem sacarose em isomaltulose}

O primeiro relato da obtenção da isomaltulose foi em 1957, quando Weidenhagen e Lorenz ${ }^{37}$ relataram a conversão de sacarose em um novo e desconhecido dissacarídeo redutor pela ação da bactéria Protaminobacter rubrum CBS 574.77, isolada a partir de subprodutos de açúcar de beterraba. O dissacarídeo foi identificado como isomaltulose e nomeado como palatinose, derivado de "palatinum", nome da província alemã onde o dissacarídeo foi encontrado. A partir deste estudo, outros trabalhos foram realizados enfocando o isolamento e cultivo de microrganismos, a produção e caracterização da enzima e a conversão de sacarose em isomaltulose. Lund e Wyatt ${ }^{21}$ verificaram que a bactéria Erwinia carotovora var. atroseptica GI20 produziu isomaltulose e pequenas quantidades de outros açúcares, como glicose, frutose, maltose, sacarose e seus isômeros, como turanose, maltulose, leucrose e trealulose (Figura 1).

A maioria dos microrganismos produtores de glicosiltransferase, que converte sacarose em isomaltulose, foi fermentada em meio

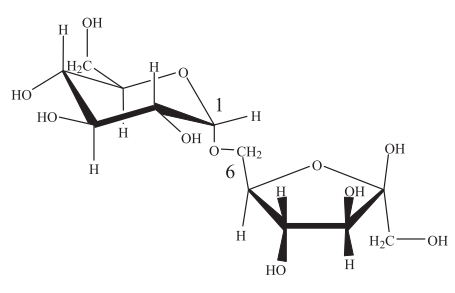

Isomaltulose

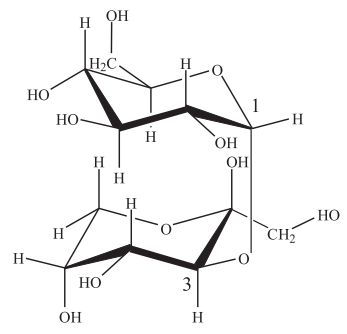

Turanose

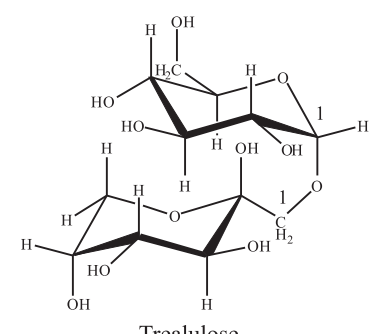

Trealulose

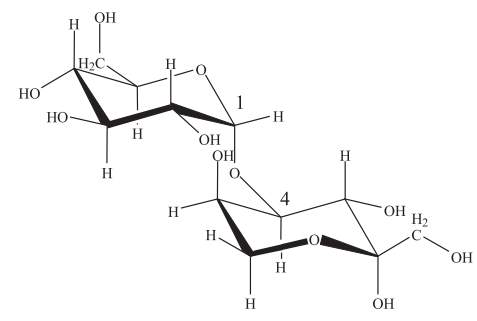

Maltulose

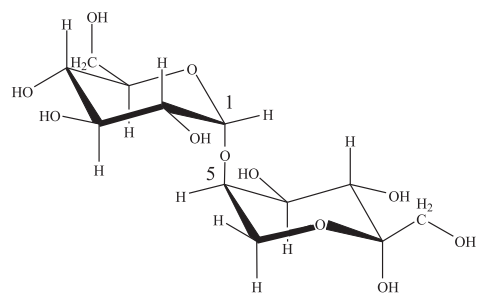

Leucrose de cultivo contendo peptona, sacarose, extrato de levedura, extrato de carne e sais. Tais componentes possuem alto custo, encarecendo a produção de isomaltulose. Alguns trabalhos têm utilizado subprodutos e resíduos agroindustriais como componentes de meio de cultivo na tentativa de diminuir o custo de fermentação. Tem-se utilizado melaço de cana-de-açúcar como substituto da sacarose como fonte de carbono, água de maceração de milho como alternativa à peptona e extrato de carne e levedura, como fonte de carbono e nitrogênio. A Tabela 1 relaciona os microrganismos produtores de glicosiltransferase que convertem sacarose em isomaltulose, os meios de cultivo utilizados para a fermentação dos microrganismos e os produtos obtidos a partir de sacarose.

\section{Características da glicosiltransferase}

A glicosiltransferase microbiana é uma enzima intracelular e está localizada no espaço periplasmático das células, disponibilidade comercial da glicosiltransferase para a conversão de sacarose em isomaltulose, sendo pouco os trabalhos que utilizam a enzima purificada para a conversão $0^{27.28,29,46}$. Diversos estudos foram realizados visando a purificação, caracterização e o esclarecimento do mecanismo bioquímico da conversão de sacarose em isomaltulose. Constatou-se que a enzima de Erwinia rhapontici que mediava a bioconversão de isomaltulose estava localizada no espaço periplasmático das células, o que facilitaria seu uso como um biocatalisador industrial ${ }^{10,39}$. A enzima foi descrita como sacarose específica com um mecanismo de transglicosilação intramolecular em que ambos os resíduos de glicose e frutose estavam associadas à enzima. A reação, não sendo seletiva, formava simultaneamente isomaltulose e trealulose a partir da re-glicosilação com as posições do carbono 6 e 1 da frutofuranose. Verificou-se que a razão isomaltulose/trealulose foi constante nos estágios iniciais da reação sob diferentes condições de $\mathrm{pH}$, temperatura e concentração do substrato. No entanto, após extensa incubação e quando toda sacarose foi consumida, houve uma lenta queda da concentração de isomaltulose e um lento aumento da trealulose. Em outro ensaio, isomaltulose e trealulose foram incubadas com enzima purificada e células livres e verificou-se que houve formação de trealulose a partir de isomaltulose e que não houve formação de isomaltulose a partir de trealulose, sugerindo que a conversão da isomaltulose seria reversível e a da trealulose, irreversível.

As glicosiltransferases que convertem a sacarose em isomaltulose descritas na literatura apresentam atividade ótima na faixa de $\mathrm{pH} 5,0$ a 6,5 e temperatura de 30 a $40{ }^{\circ} \mathrm{C}$ e são citadas como sendo termossensíveis ${ }^{26-29,46-48}$. A enzima não purificada de Serratia plymuthica ATCC 15928 foi obtida após centrifugação a 10.000 rpm, por 20 min e rompimento da massa celular em prensa- $\mathrm{X}^{26}$. Após separação em Bio-Gel foi obtido um grau de pureza 25 vezes superior em relação à enzima não purificada, que apresentou atividade ótima em $\mathrm{pH} 6,0$ e a $30{ }^{\circ} \mathrm{C}$. Park et al. ${ }^{28,29}$ caracterizaram a enzima obtida da bactéria Klebsiella sp capaz de converter sacarose em isomaltulose. A enzima purificada apresentou melhor atividade entre pH 6 e 6,5 e temperatura ótima de $35^{\circ} \mathrm{C}$.

A enzima denominada sacarose isomerase, clonada em Escherichia coli por Wu e $\mathrm{Birch}^{48}$, apresentou atividade máxima em pH 5,0 a 30 e $35^{\circ} \mathrm{C}$. A enzima purificada apresentou $\mathrm{K}_{\mathrm{m}}$ de $39,9 \mathrm{mM} \mathrm{e}_{\max }$ de 423 $\mathrm{U} / \mathrm{mg}$ para sacarose. A enzima converteu sacarose em isomaltulose e trealulose na proporção 8:1, respectivamente. A glicosiltransferase de Pseudomonas mesoacidophila MX-45, que produz maior proporção de trealulose a partir de sacarose, foi purificada ${ }^{47}$. A enzima apresentou atividade ótima em $\mathrm{pH} 5,8$ a $40{ }^{\circ} \mathrm{C}$, e maior estabilidade na faixa de $\mathrm{pH} 5,1$ a 6,7 e em temperaturas inferiores a $40{ }^{\circ} \mathrm{C}$. A enzima purificada converteu sacarose em isomaltulose e trealulose, e a razão 
Tabela 1. Microrganismos produtores de glicosiltransferase que convertem sacarose em isomaltulose, meios de fermentação e produtos formados

\begin{tabular}{ll}
\hline Microrganismos & Composição do meio de cultivo \\
produtores de & para fermentação do \\
glicosiltransferase & microrganismo
\end{tabular}

Agrobacterium

radiobacter $\mathrm{MX}-232^{38}$

Erwinia rhapontici

ATCC29283 36

Erwinia rhapontici

NCPPB1578 ${ }^{39}$

Erwinia rhapontici

NCPPB $1578^{40}$

Erwinia sp. ${ }^{41}$

Erwinia sp. ${ }^{30}$

Klebsiella planticola

CCRC191129

Klebsiella planticola
$\mathrm{MX} 10^{18}$

Klebsiella sp. $^{28,29}$

Klebsiella sp.

$\mathrm{LX}^{42}$

Pantoeae dispersa

$\mathrm{UQ68J}^{43}$

Protaminobacter rubrum ${ }^{31}$

Protaminobacter rubrum CBS574.7732

Pseudomonas

mesoacidophila MX-4544

Serratia plymuthica ${ }^{3}$

Serratia plymuthica ${ }^{3}$

Serratia plymuthica ${ }^{45}$

Serratia plymuthica ${ }^{31}$

Serratia plymuthica

ATCC $15928^{26}$

Serratia plymuthica

ATCC15928 ${ }^{27}$
Peptona $1 \%$, melaço $10 \%$, extrato de carne

$0,3 \%$, extrato de levedura $0,5 \%, \mathrm{NaCl} 0,3 \%$

e $\mathrm{Na}_{2} \mathrm{HPO}_{4} .12 \mathrm{H}_{2} \mathrm{O} 0,2 \%$

Sacarose 5\%, extrato de levedura $1 \%$ e

$\mathrm{Na}_{2} \mathrm{HPO}_{4} \cdot 12 \mathrm{H}_{2} \mathrm{O}$

Peptona $1 \%$, sacarose $4 \%$ e extrato de carne $0,4 \%$

Caseinato de peptona $0,6 \%$, sacarose $4 \%$, $\mathrm{MgNO}_{3} 0,3 \%$ e $\mathrm{NaCl} 0,5 \%$

Melaço de cana-de-açúcar 15\%, água de maceração de milho $2 \%$ e extrato de levedura comercial $1,5 \%$

Melaço de cana-de-açúcar $12 \%$, peptona $4 \%$ e extrato de carne $0,4 \%$

Caldo de soja $3 \%$, sacarose $7 \%$, triptona

bacteriológica $2 \%$ e $\mathrm{NaCl} 0,5 \%$

Peptona $1 \%$, sacarose $10 \%$, extrato de carne $0,3 \%$, extrato de levedura $0,5 \%$, $\mathrm{Na}_{2} \mathrm{HPO}_{4} \cdot 12 \mathrm{H}_{2} \mathrm{O} 0,2 \%$ e $\mathrm{NaCl} 0,3 \%$

Peptona $1 \%$, sacarose $4 \%$ e

extrato de carne $0,4 \%$

Peptona $1 \%$, sacarose $0,4 \%$ e extrato de levedura $0,04 \%$

Triptona $1,2 \%$, sacarose $4 \%$, extrato de levedura $2,4 \%$, glicerol $0,4 \%$ e $\mathrm{KH}_{2} \mathrm{PO}_{4} 0,09 \mathrm{~mol} / \mathrm{L}$

Peptona $2 \%$, sacarose $10 \%$, extrato de carne $0,3 \%$, extrato de levedura $1 \%$, $\mathrm{Na}_{2} \mathrm{HPO}_{4} 0,4 \%$ e $\mathrm{CaCl}_{2} 0,6 \%$ Peptona $0,5 \%$, sacarose $5 \%$, extrato de carne $0,3 \%$ e $\mathrm{Na}_{2} \mathrm{HPO}_{4} 0,01 \mathrm{M}$

Peptona $1 \%$, melaço $10 \%$, extrato de carne $0,3 \%$, extrato de levedura $0,5 \%$, $\mathrm{NaCl} 0,3 \%$ e $\mathrm{Na}_{2} \mathrm{HPO}_{4} .12 \mathrm{H}_{2} \mathrm{O} 0,2 \%$ Peptona $1 \%$, sacarose $5 \%$, extrato de carne $0,3 \%$, extrato de levedura $0,5 \%$, $\mathrm{Na}_{2} \mathrm{HPO}_{4} 0,2 \%$ e $\mathrm{NaCl} 0,3 \%$

Peptona $1 \%$, sacarose $5 \%$, extrato de carne $0,3 \%$, extrato de levedura $0,5 \%$, $\mathrm{Na}_{2} \mathrm{HPO}_{4} 0,2 \%$ e $\mathrm{NaCl} 0,3 \%$

Peptona $1 \%$, sacarose $4,9 \%$, extrato de carne $0,25 \%$, extrato de levedura $0,6 \%$, $\mathrm{Na}_{2} \mathrm{HPO}_{4} 0,14 \%$ e $\mathrm{NaCl} 0,3 \%$

Peptona $2 \%$, sacarose $10 \%$, extrato de carne $0,3 \%$, extrato de levedura $1 \%, \mathrm{CaCl}_{2} 0,6 \%$ e $\mathrm{Na}_{2} \mathrm{HPO}_{4} 0,4 \%$

Peptona $1 \%$, sacarose $4 \%$ e extrato de carne $0,4 \%$

Sacarose $5 \%$, extrato de levedura $0,75 \%$, $\mathrm{KH}_{2} \mathrm{PO}_{4} 0,5 \%, \mathrm{MgSO}_{4} 0,04 \%$ e $\left(\mathrm{NH}_{4}\right)_{2} \mathrm{SO}_{4} 0,1 \%$
Rendimento (\%) de isomaltulose, trealulose e outros carboidratos utilizando-se células livres, células imobilizadas ou glicosiltransferase em diferentes concentrações de sacarose

$9,9 \%$ de isomaltulose, $88,8 \%$ de trealulose e $1,4 \%$ de sacarose utilizando-se célula livres e sacarose $20 \%$

$89 \%$ de isomaltulose utilizando-se células imobilizadas e sacarose $55 \%$

$85 \%$ de isomaltulose e $15 \%$ de trealulose utilizando-se células imobilizadas e sacarose $55 \%$

$\sim 46,7 \%$ de isomaltulose utilizando-se células imobilizadas e sacarose $30 \%$

$72,1 \%$ de isomaltulose utilizando-se células livres e sacarose $35 \%$

$50 \%$ de isomaltulose utilizando-se células imobilizadas e sacarose $20-30 \%$

$76-84 \%$ de isomaltulose, $14-16 \%$ de trealulose, $2-6 \%$ de glicose e $2-3 \%$ de frutose utilizando-se células livres e sacarose $50 \%$

$63,9 \%$ de isomaltulose, $30,2 \%$ de trealulose e $4,3 \%$ de sacarose utilizando-se células imobilizadas e sacarose $20 \%$

$86 \%$ de isomaltulose utilizando-se enzima purificada e sacarose $4 \%$

$87,4 \%$ isomaltulose e $11,6 \%$ de trealulose e $<1 \%$ de glicose utilizando-se enzima purificada e sacarose $4 \%$

$80,1 \%$ de isomaltulose, $4 \%$ de trealulose, $9,7 \%$ de glicose, $4,6 \%$ de frutose e $1,6 \%$ de sacarose utilizando-se células livres e sacarose $25 \%$

$>90 \%$ de isomaltulose utilizando-se células livres e sacarose $25 \%$

$85,9 \%$ de isomaltulose e $8 \%$ de trealulose utilizando-se células livres e sacarose $35 \%$

$9,2 \%$ de isomaltulose, $88,4 \%$ de trealulose e $2,4 \%$ de sacarose utilizando-se células livres e sacarose $20 \%$

$79,8 \%$ de isomaltulose, $7 \%$ de trealulose, $1,2 \%$ de isomaltose, $2,9 \%$ de glicose, $5,7 \%$ de frutose, $0,9 \%$ de sacarose e $2,6 \%$ de outros utilizando-se células imobilizadas e sacarose $40 \%$

$80 \%$ de isomaltulose, $7 \%$ de trealulose, $1,3 \%$ de isomaltose, $2,9 \%$ de glicose, $5,8 \%$ de frutose, $0,2 \%$ de sacarose e $2,8 \%$ de outros utilizando-se células livres e sacarose $40 \%$ $94 \%$ de isomaltulose, $2,3 \%$ de isomaltose, $0,8 \%$ de glicose e $2,9 \%$ de frutose utilizando-se células imobilizadas e sacarose $50 \%$

$>90 \%$ de isomaltulose utilizando-se células livres e sacarose $25 \%$

$87 \%$ de isomaltulose utilizando-se enzima purificada e sacarose $40 \%$

$72,6 \%$ de isomaltulose, $6,6 \%$ de trealulose, $10,1 \%$ de glicose e $10,1 \%$ de frutose utilizando-se enzima purificada e sacarose $9 \%$ 
entre os açúcares aumentou em temperaturas mais baixas. A glicosiltransferase apresentou atividade máxima de 13,89 U/mg.

Véronèse e Perlot ${ }^{49}$ investigaram o mecanismo de catálise enzimática envolvendo o sítio ativo da glicosiltransferase produzida por Protaminobacter rubrum, Serratia plymuthica e Erwinia rhapontici. Diferentes monossacarídeos foram utilizados na mistura de reação para verificar o efeito inibidor ou ativador na formação de isomaltulose. Verificou-se que a maioria dos monossacarídeos apresentou efeito inibitório ou nenhum efeito. $\mathrm{O}$ modo de ação da glicosiltransferase de Protaminobacter rubrum também foi estudado ${ }^{19}$. A enzima catalisou a transglicosilação intramolecular da sacarose formando isomaltulose e também a transglicosilação intermolecular da sacarose, para outros aceptores, formando outros derivados de sacarose.

Celestino $^{46}$ estudou a produção, purificação e caracterização bioquímica da glicosiltransferase intracelular de Erwinia sp. D12. No estudo da produção da glicosiltransferase, em fermentador de 2 $\mathrm{L}$, verificou-se que a enzima foi produzida na fase exponencial de crescimento, sendo que a produção máxima foi obtida após $3 \mathrm{~h}$ de fermentação a $28{ }^{\circ} \mathrm{C}$, e após $4 \mathrm{~h}$ de incubação a 30 e $35^{\circ} \mathrm{C}$. A enzima purificada apresentou atividade ótima em $\mathrm{pH} 6,0$ e a $40^{\circ} \mathrm{C}$. A glicosiltransferase purificada mostrou-se termossensível, sendo inativada após $1 \mathrm{~h}$ de tratamento a temperaturas superiores a $39{ }^{\circ} \mathrm{C}$ e após $3 \mathrm{~h}$, a $35^{\circ} \mathrm{C}$ na ausência de substrato. A enzima mostrou-se estável na faixa de $\mathrm{pH} 5,7$ a 6,3 , após 24 h de incubação, a $5^{\circ} \mathrm{C}$. Utilizando-se a glicosiltransferase e solução de sacarose 5 e $10 \%$ $(\mathrm{p} / \mathrm{v})$ foram obtidos 73,5 e $72,3 \%$ de isomaltulose, respectivamente, após 4 h de reação a $40{ }^{\circ} \mathrm{C}$.

A $\alpha$-glicosiltransferase purificada de Serratia plymutica ATCC 15928 converteu sacarose em $72,6 \%$ de isomaltulose, $6,6 \%$ de trealulose, $10,1 \%$ glicose e $10,1 \%$ de frutose ${ }^{27}$. A enzima foi obtida pelo rompimento celular em sonicador. $\mathrm{O}$ sobrenadante contendo a enzima foi obtido por centrifugação a $20.000 \mathrm{rpm}$, durante $30 \mathrm{~min}$. A conversão máxima de solução de sacarose $292 \mathrm{mM}$ ocorreu em $\mathrm{pH} 6,2$ e a temperatura de $30^{\circ} \mathrm{C}$. A proporção dos produtos foi dependente da temperatura de reação e o aumento da temperatura aumentou a formação de frutose. Verificou-se que a adição de glicose ou frutose à mistura de reação também alterou a proporção dos produtos, sendo que a glicose atuou como inibidor competitivo. Foi observado também que, a reversibilidade da reação ocorria somente com a isomaltulose e não com a trealulose.

\section{IMOBILIZAÇÃO}

A primeira aplicação industrial utilizando-se um sistema de células imobilizadas foi na produção contínua de ácido Laspártico $^{50}$. Nos últimos anos houve um grande aumento das pesquisas na área de biocatálise envolvendo a imobilização de enzimas e células inteiras de microrganismos ${ }^{51,52}$. A imobilização de microrganismos pode ser definida como qualquer técnica que limita a livre migração das células ${ }^{51,53}$ ou o confinamento físico ou localização de células intactas em uma certa região do espaço com a preservação de desejadas atividades catalíticas ${ }^{51,54}$. As células imobilizadas em uma matriz podem ser protegidas de condições ambientais desfavoráveis como $\mathrm{pH}$, temperatura, solventes orgânicos e substâncias tóxicas, podendo ser manipuladas e recuperadas das soluções ${ }^{55-57}$. Para aplicação na produção de alimentos, a imobilização de células deve ser realizada em uma matriz GRAS ("Generally Recognized As Safe") 58 . Além de seguro, a matriz de imobilização não pode ser de alto custo, deve ser estável, reutilizável e permitir a imobilização de altas concentrações de células com mínimas limitações de transferência de $\operatorname{massa}^{59}$.
As técnicas de imobilização de células microbianas são divididas em quatro grandes categorias baseadas no mecanismo físico empregado: adsorção na superfície de um suporte sólido; aprisionamento no interior de um suporte poroso; agregação natural por floculação ou induzidas com agentes de reticulação ou ligantes; e contenção física dentro de uma barreira ${ }^{56,57,60}$.

\section{Imobilização por adsorção na superfície de um suporte sólido}

A imobilização de células em um suporte sólido ocorre pela adsorção física através de forças eletrostáticas ou pela ligação covalente entre a membrana celular e o suporte ${ }^{56}$. A adsorção pode ser induzida por agentes como óxidos metálicos, glutaraldeído ou aminossilanos. No entanto, para a produção de alimentos e bebidas, a adesão natural é desejável em substituição ao uso de indutores tóxicos ou instáveis. A imobilização natural é considerada uma técnica simples e as condições de realização são suaves; no entanto, como não há barreiras entre as células e a solução, o desligamento e seu religamento são possíveis devido ao estabelecimento de um equilíbrio entre células adsorvidas e livres na suspensão ${ }^{57}$. Existem diferentes tipos de suportes que vêm sendo utilizados atualmente ${ }^{61}$, tais como materiais celulósicos (madeira) e materiais inorgânicos (porcelana porosa e vidro poroso) ${ }^{56}$.

\section{Agregação celular (floculação)}

A floculação tem sido definida como a capacidade de agregação natural das células para formar uma grande unidade ${ }^{57}$ ou como uma propriedade das células em suspensão em aderir em grupos e rapidamente sedimentar ${ }^{56,62}$. A habilidade em formar agregados pode ser observada principalmente em fungos, leveduras e células vegetais. Agentes floculantes podem ser utilizados para a indução da agregação das células que não são naturalmente floculantes. A floculação de leveduras tem sido utilizada na elaboração de cerveja, devido a sua simplicidade e baixo custo, e é um fator de grande importância por afetar a produtividade de fermentação e qualidade da bebida ${ }^{57}$.

\section{Contenção física dentro de uma barreira}

A contenção dentro de uma matriz pode ser realizada pelo uso de membranas microporosas ou pela contenção das células em microcápsulas ${ }^{55,60}$. Esta técnica de imobilização é utilizada quando se requer produto livre de células, mínima transferência de compostos ou quando produtos de alta massa molecular precisam ser separados a partir do efluente ${ }^{57}$. Problemas inerentes a esta técnica são as limitações pela transferência de massa e a possível saturação da membrana pelo crescimento celular ${ }^{63}$.

\section{Aprisionamento no interior de um suporte poroso}

Os métodos de aprisionamento são baseados na inclusão e retenção de células dentro de uma rígida rede ou interstícios das fibras ou poros do suporte para impedir que as células se difundam no meio circunvizinho, enquanto ainda permite a transferência de nutrientes e metabólitos ${ }^{56}$. A técnica de aprisionamento de microrganismos no interior de um suporte poroso é a metodologia de imobilização mais utilizada para a conversão de sacarose em isomaltulose. Grânulos esféricos de polímeros com diâmetros variando de 0,3 a 3,0 mm e imobilização de biomassa são produzidos utilizando-se extrusão ou técnicas de emulsificação, por temperatura ( $\kappa$-carragena, gelana, agarose e gelatina) ou por ionização (alginato e quitosana) $)^{52,64}$. 
O alginato é um dos suportes mais utilizados para a imobilização de células microbianas inteiras por ser uma metodologia simples e barata; além de ser uma técnica reprodutível que utiliza condições suaves durante o processo de imobilização ${ }^{65-71}$. Os alginatos são heteropolímeros lineares de ácidos carboxílicos compostos de subunidades monoméricas de $\beta$-D-ácido manurônico (M) e $\alpha$-Lácido gulurônico $(\mathrm{G})$ interligados por ligações 1,4-glicosídicas. Estes monômeros podem ser organizados em cadeias consecutivas de resíduos $\mathrm{G}(\mathrm{G})_{\mathrm{n}}$, de resíduos $\mathrm{M}(\mathrm{M})$, ou alternando resíduos $\mathrm{M}$ e $\mathrm{G}(\mathrm{MG})_{\mathrm{n}}$ (Figura 2). A quantidade relativa de cada tipo de cadeia varia entre os diferentes alginatos. Existem distintas diferenças estruturais entre os tipos de cadeias ${ }^{72-74}$. Os (MG) formam as cadeias mais flexíveis e são mais solúveis em valores baixos de $\mathrm{pH}$. Os $(\mathrm{G})_{\mathrm{n}}$ formam cadeias rígidas em que duas cadeias $\mathrm{G}$, com mais de seis resíduos cada podem ser ligados por íons bivalentes levando a formação de gel. Em valores de $\mathrm{pH}$ baixos, alginatos de alta massa molar protonados podem formar géis ácidos fracos. Nestes géis, à maior parte são cadeias homopoliméricas as quais formam junções, mas a estabilidade depende do conteúdo de cadeias G. Géis com grande quantidade de $(\mathrm{G})_{\mathrm{n}}$ exibem alta porosidade, baixo encolhimento durante a formação do gel e menor inchamento após secagem, no entanto, têm maior propensão em apresentar sinérese. Com o aumento da quantidade de $(\mathrm{M})_{\mathrm{n}}$, os géis tornam-se mais macios e apresentam poros de menor tamanho.
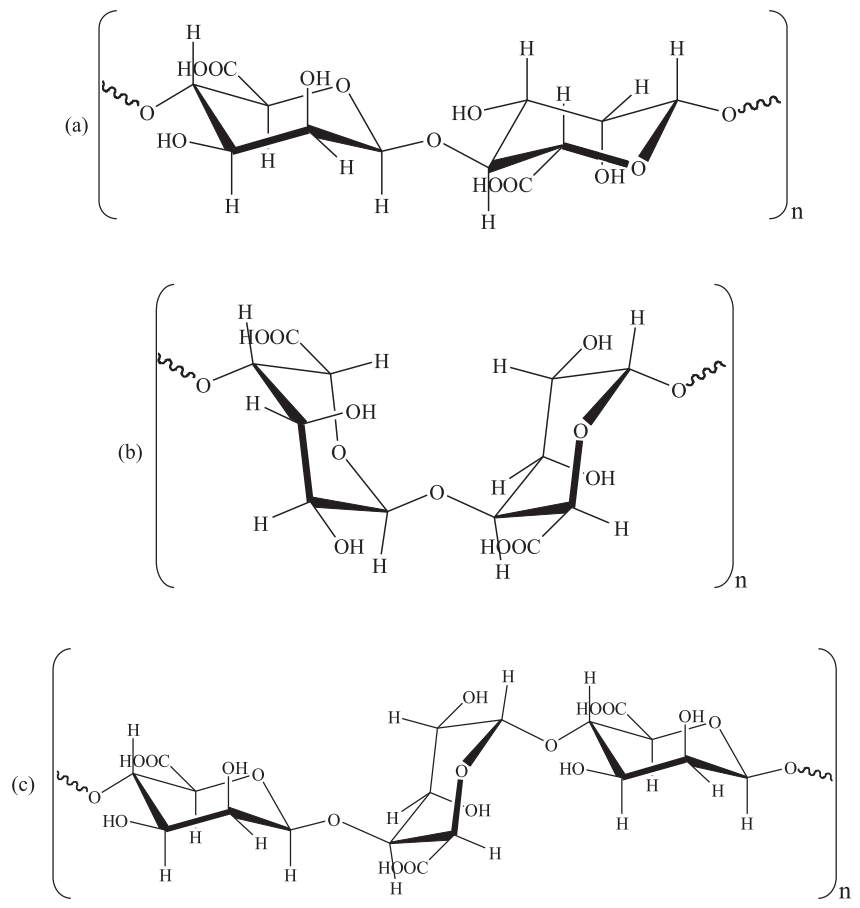

Figura 2. Composição de alginatos: (a) cadeia de resíduos de ácidos manurônicos; (b) cadeia de resíduos de ácidos gulurônicos; (c) cadeia de resíduos de ácidos manurônicos e ácidos gulurônicos alternados

Na imobilização com alginato uma suspensão de microrganismos é misturada a uma solução de alginato de sódio, suficiente para formar um gel firme. Essa mistura é submetida à extrusão com auxílio de mangueiras e bomba peristáltica, sendo gotejada em solução contendo sais de íons bivalentes como cloreto de cálcio, formando grânulos. Após gelificação, os microrganismos são retidos ou aprisionados dentro do gel. Durante a permanência na solução salina, os íons cálcio são transportados para o centro da esfera e um estado de equilíbrio é atingido variando de $15 \mathrm{~min}$ a $12 \mathrm{~h}^{67}$ (Figura 3). O tempo depende das condições experimentais como temperatura, concentra-

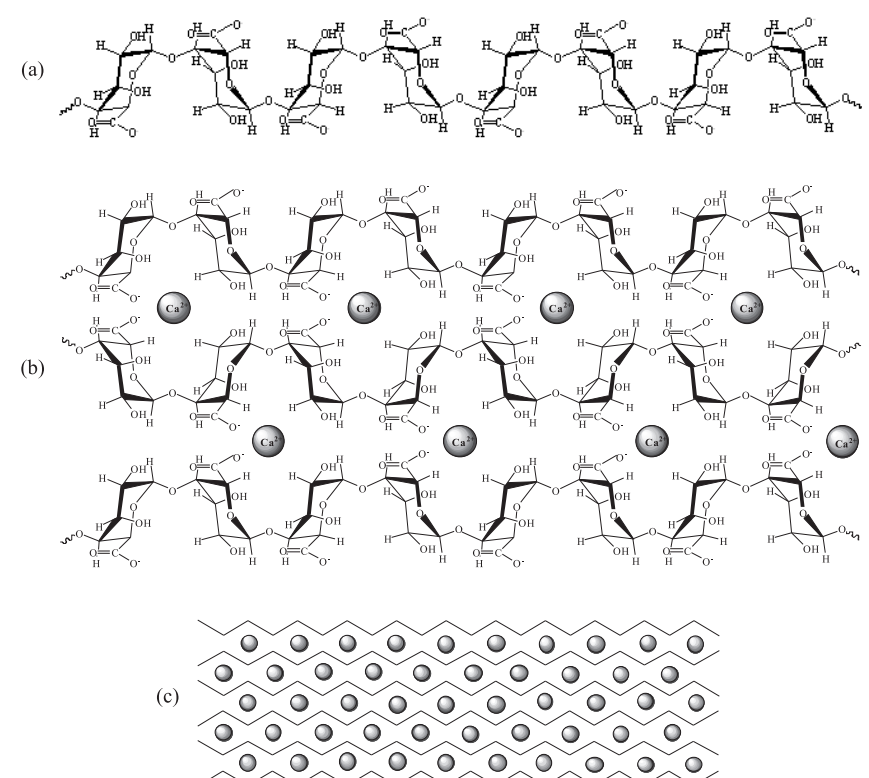

Figura 3. Formação do gel de alginato de cálcio: (a) homopolímeros de unidade de ácido gulurônico em solução; (b) ligação entre as cadeias homopoliméricas através dos íons cálcio situados entre os grupos com carga negativa; (c) formação da rede de gel com cadeias homopoliméricas unidas através dos íons cálcio

ção do sal, diâmetro da esfera, tipo e concentração de alginato, concentração da suspensão celular. Durante o procedimento de maturação da esfera, em solução de cloreto de cálcio, o aumento do volume pode chegar a $40 \%$ em relação ao tamanho original ${ }^{66,72}$.

Alguns aspectos durante a imobilização devem ser observados como a estabilidade mecânica, que pode diminuir com o tempo devido à baixa concentração de alginato ou à grande quantidade de células na suspensão; limitações difusionais dependendo do tipo e concentração do gel. Uma das principais causas do rompimento dos grânulos de alginato é a quelação dos íons cálcio com outros compostos do meio, principalmente por íons fosfato, que pode ser minimizada adicionando-se mais íons $\mathrm{Ca}^{2+}$ ao meio. A atividade das células imobilizadas depende do tamanho da superfície das esferas, da porosidade do gel formado e das características hidrofílicas do suporte. A polietilenoimina é uma amina polimérica alifática polibásica utilizada nas técnicas de imobilização como um constituinte menor, dando uma característica hidrofílica e maior força mecânica às preparações de células imobilizadas. Pode também ser usada como um constituinte primário do suporte, como agente de reticulação ou ligação ${ }^{75}$. O glutaraldeído é empregado como aditivo no processo de imobilização, como agente de ligação ou reticulação na preparação de esferas de alginato de cálcio ${ }^{55}$.

Shimizu et $a l .{ }^{5}$ estudaram a produção de isomaltulose por células imobilizadas de Serratia plymuthica NCIB 8285 em alginato de cálcio utilizando aditivos glutaraldeído e polietilenoimina. A massa celular foi ressuspendida em solução de alginato de sódio $2 \%(\mathrm{p} / \mathrm{v})$ e gotejada em solução de cloreto de cálcio $0,1 \mathrm{~N}$ sob agitação, por $2 \mathrm{~h}$. Os grânulos formados foram recuperados por filtração e lavados com água. Todos os experimentos foram realizados em batelada, com sucessiva reutilização dos grânulos e temperatura próxima de $25{ }^{\circ} \mathrm{C}$ para evitar a inativação da $\alpha$ glicosiltransferase. A maior estabilidade durante a conversão de solução de sacarose $30 \%$ (p/p) ocorreu quando os grânulos contendo células imobilizadas foram tratados com solução de polietilenoimina 1,5\% (30 g de grânulos para cada $100 \mathrm{~mL}$ de solução previamente neutralizada a pH 5,0-5,8 com ácido clorídrico) 
e solução de glutaraldeído $1 \%$ (30 g de grânulos para cada 100 mL de solução, a $25^{\circ} \mathrm{C}$, por $30 \mathrm{~min}$ ).

Em estudos comparativos, foi demonstrado que células imobilizadas de Erwinia rhapontici NCPPB 1578 em grânulos de gel de alginato de cálcio apresentaram estabilidade 350 vezes maior que as células livres, alcançando-se uma meia vida de aproximadamente $8.600 \mathrm{~h}^{25}$. Após fermentação em frascos agitados a $30{ }^{\circ} \mathrm{C}$, as células foram recuperadas por centrifugação. Para a imobilização a suspensão celular $20 \%$ (massa celular úmida/v) foi misturada com solução de alginato de sódio $5 \%(\mathrm{p} / \mathrm{v})$ a pH 6,0 e gotejada em solução de $\mathrm{CaCl}_{2}$ 0,1 M pH 6,5, a temperatura ambiente para a formação de grânulos. As células imobilizadas foram dispostas em colunas $(200 \times 15 \mathrm{~cm})$, mantidas a $30^{\circ} \mathrm{C}$ e alimentadas com solução de sacarose 1,6 M ajustada a pH 7,0. As células imobilizadas foram mais eficientes obtendo-se conversão de $90 \%$ em isomaltulose. A atividade das células imobilizadas diminuiu com o aumento da concentração das células, o que normalmente ocorre em sistemas difusionalmente limitados e também diminuiu a resistência mecânica.

Células imobilizadas de Erwinia sp. foram utilizadas para a conversão de sacarose em isomaltulose ${ }^{35}$. Foram utilizados diversos materiais para imobilização como ágar, k-carragena, goma xantana, poliacrilamida, no entanto, o alginato de cálcio apresentou maior eficiência. A massa celular foi ressuspendida em solução de alginato de sódio $5 \%(\mathrm{p} / \mathrm{v})$ para formar, no final, uma suspensão com $20 \%$ de células (p/v). A suspensão foi gotejada em solução de cloreto de cálcio $0,1 \mathrm{M}$ a $30^{\circ} \mathrm{C}$, contendo sacarose $15 \%$ $(\mathrm{p} / \mathrm{v})$ com a finalidade de estabilizar a atividade enzimática das células. As células imobilizadas foram dispostas em colunas (300 x $50 \mathrm{~mm}$ ) e mantidas a $30^{\circ} \mathrm{C}$. Foi demonstrado que a estabilidade e produtividade aumentaram com o incremento da concentração de sacarose, sendo que foi obtida maior produção de isomaltulose utilizando-se solução de sacarose $55 \%$ (p/v) e pH 7. Foram obtidos cerca de 85 a $90 \%$ de conversão inicial com meia vida de $8.500 \mathrm{~h}$.

Um novo método foi descrito para a obtenção de isomaltulose utilizando-se células imobilizadas de Protaminobacter rubrum, empregando-se 6-cloro-6-dioxi-sacarose em vez de sacarose ${ }^{7}$. As células foram imobilizadas em gel de alginato de cálcio. A atividade máxima das células imobilizadas, em pH 5,5, ocorreu em $3 \mathrm{~h}$ e foi proporcional a quantidade de células, sendo obtida conversão de 18, 30 e $44 \%$ para 10, 20 e $40 \mathrm{mg}$ de células $/ \mathrm{mL}$ de solução, respectivamente.

Tsuyuki et al. ${ }^{18}$ utilizaram a bactéria Klebsiella planticola MX 10 para converter sacarose em isomaltulose. A massa celular foi misturada com solução de alginato de sódio $4 \%$ (p/v) na proporção $1: 1$ (v:v) e a suspensão celular foi gotejada em solução de $\mathrm{CaCl}_{2}$ 0,25 M sob agitação, formando grânulos com células imobilizadas. Os grânulos foram mantidos na solução por $1 \mathrm{~h}$ e, posteriormente, lavados com água destilada e colocados em solução de polietilenoimina $2 \% \mathrm{pH} 5,6$. Após 5 min, os grânulos foram separados e misturados com solução de glutaraldeído $0,5 \%$ a $5{ }^{\circ} \mathrm{C}$, por $20 \mathrm{~min}$. As células imobilizadas foram separadas da solução de glutaraldeído e lavadas com água destilada. As células imobilizadas tratadas com polietilenoimina e glutaraldeído converteram totalmente a solução $25 \%$ de sacarose sendo obtidos $65,4 \%$ de isomaltulose e $29,7 \%$ de trealulose.

A bactéria Klebsiella sp. LX3 produtora de enzima denominada isomaltulose sintase, capaz de converter sacarose em isomaltulose e trealulose, foi imobilizada com solução de alginato de sódio $2 \%(\mathrm{p} / \mathrm{v})$ em solução de $\mathrm{CaCl}_{2}, 0,65 \%(\mathrm{p} / \mathrm{v})$, e dispostas em colunas de leito empacotado ${ }^{42}$. Utilizando-se solução $10 \%$ de sacarose como substrato, foram obtidos $87 \%$ de isomaltulose, $11,6 \%$ de trealulose e $1 \%$ de glicose.

Ahn et al. ${ }^{36}$ utilizaram a linhagem Erwinia rhapontici ATCC
29283 para converter sacarose em isomaltulose. As células foram recuperadas do meio de fermentação por centrifugação a $1.000 \mathrm{x}$ g a $4{ }^{\circ} \mathrm{C}$ por 20 min e lavadas com $\mathrm{NaCl} 0,9 \%(\mathrm{p} / \mathrm{v})$. A suspensão celular $40 \%$ (p/v) foi misturada com igual volume de solução de alginato de sódio $5 \%(\mathrm{p} / \mathrm{v})$. A mistura foi gotejada, com auxílio de bomba peristáltica, em solução de cloreto de cálcio $0,15 \mathrm{M}$ para formar as células imobilizadas. Após permanecerem uma noite em solução de cloreto de cálcio a $4{ }^{\circ} \mathrm{C}$, as células foram tratadas com solução de sacarose $55 \%(\mathrm{p} / \mathrm{v})$ a $30{ }^{\circ} \mathrm{C}$ por 2 dias. Os grânulos foram empacotados em colunas $(180$ x $50 \mathrm{~cm}$ e capacidade de $300 \mathrm{~mL}$ ) a $30{ }^{\circ} \mathrm{C}$ e alimentados com solução de sacarose $55 \%(\mathrm{p} / \mathrm{v}) \mathrm{pH} 7,0$. Foram testadas as temperaturas de 27,30 e 33 ${ }^{\circ} \mathrm{C}$ e os rendimentos iniciais de isomaltulose foram respectivamente, 79,89 e $85 \%$ e diminuíram para 67,79 e $57 \%$ após 60 dias, respectivamente.

Moraes et $a l .{ }^{76}$ verificaram que a produção de isomaltulose a partir de sacarose, utilizando-se células de Erwinia sp. D12 imobilizadas em alginato de cálcio em colunas de leito empacotado, foi em torno de $50 \%$ de isomaltulose com soluções de sacarose entre $20-30 \%$ a $35{ }^{\circ} \mathrm{C}$. Posteriormente, Kawaguti et al..$^{23,24}$ estudaram a influência da concentração de alginato de sódio, da suspensão de células e aplicação de aditivos glutaraldeído e polietilenoimina na imobilização de Erwinia sp. D12 em alginato de cálcio. As células inteiras, recuperadas após fermentação, foram ressuspendidas em água destilada e misturadas a uma solução de alginato de sódio na proporção 1:2. A mistura foi submetida à extrusão com auxílio de uma bomba peristáltica e gotejada em solução de cloreto de cálcio para a formação de esferas contendo as células imobilizadas. Verificou-se que as melhores concentrações de alginato de sódio e suspensão celular foram $2 \%(\mathrm{p} / \mathrm{v})$ e $40 \%$ (massa celular úmida/v), respectivamente. Observou-se que a melhor concentração de aditivo glutaraldeído seria de $0,06 \%$ (v/v). Utilizando-se células imobilizadas em colunas de leito empacotado e solução $35 \%$ de sacarose foram obtidas taxas de conversão acima de $50 \%$ por $282 \mathrm{~h}$.

Outros suportes para imobilização celular também têm sido descritos. Células de Protaminobacter rubrum CBS 574.77 foram imobilizadas em DEAE-celulose (dietilaminoetil-celulose) para conversão de sacarose em isomaltulose ${ }^{20}$. Para a produção de massa celular, as células foram ressuspendidas em $10 \mathrm{~mL}$ de solução salina e alíquotas de $0,1 \mathrm{~mL}$ foram inoculadas em frascos de $1 \mathrm{~L}$, contendo $300 \mathrm{~mL}$ de meio ajustado a $\mathrm{pH}$ 7,0. Os frascos foram incubados a $230 \mathrm{rpm}$ por $20 \mathrm{~h}$, a $30{ }^{\circ} \mathrm{C}$. Para a imobilização da bactéria na resina trocadora aniônica, $750 \mathrm{~mL}$ de suspensão contendo as células foram bombeadas na coluna a uma vazão de 35 $\mathrm{mL} / \mathrm{h}$, a $25^{\circ} \mathrm{C}$. Uma solução de sacarose $25 \%$ (p/v), pH 7,5 e $30{ }^{\circ} \mathrm{C}$ foi bombeada continuamente na parte inferior da coluna. Este sistema permitiu a saída de $\mathrm{CO}_{2}$, proveniente da conversão, pela parte superior da coluna. O sistema foi mantido em operação por duas semanas, sendo que a conversão diminuiu com o tempo. O sistema foi renovado pela adição de meio de cultivo esterilizado. Após a conversão foi obtido $79 \%$ de isomaltulose, $0,9 \%$ de trealulose, $0,9 \%$ de frutose, $0,4 \%$ de glicose e $18,5 \%$ de sacarose.

Krastanov e Yoshida ${ }^{3}$ estudaram a conversão de sacarose em isomaltulose por células de Serratia plymuthica imobilizadas em quitosana. As células úmidas foram ressuspendidas em solução de $\mathrm{NaCl} 0,9 \%(\mathrm{p} / \mathrm{v})$ e misturadas com solução de acetato de quitosana e glutaraldeído. Após a gelatinização, a mistura foi fragmentada em pequenas partículas, lavadas com tampão fosfato $0,1 \mathrm{M} \mathrm{pH} \mathrm{6,5}$ e mantidas em solução de $\mathrm{NaCl} 0,9 \%(\mathrm{p} / \mathrm{v})$ a $4{ }^{\circ} \mathrm{C}$ por uma noite. Utilizando as células imobilizadas em frascos erlenmeyers de 50 $\mathrm{mL}$ sob agitação verificaram o efeito da temperatura, do $\mathrm{pH}$ e da concentração do substrato na atividade enzimática. Observaram que os parâmetros ótimos foram temperatura $44-45^{\circ} \mathrm{C}, \mathrm{pH}$ 6,2-6,3 e 
concentração de substrato de $40 \%$ de sacarose, no qual foram obtidos $80 \%$ de isomaltulose e $7 \%$ de trealulose. Posteriormente, foi investigada a conversão de sacarose em isomaltulose comparandose os processos em batelada e contínuo, utilizando células imobilizadas de Serratia plymuthica em quitosana ${ }^{45}$. No processo em batelada foi obtida uma produtividade específica entre 0,76 e 1,15/ $\mathrm{h}$ ( $\mathrm{kg}$ de sacarose convertida/kg de biocatalisador). No processo contínuo utilizando-se colunas de leito empacotado foi estudado o efeito da concentração do substrato sacarose (30-70\%), da temperatura $\left(30-60^{\circ} \mathrm{C}\right)$ e do tempo de residência do substrato na produtividade volumétrica ( $\mathrm{kg}$ de produto formado/L de biocatalisador/h) específica do biocatalisador. A conversão de $98-100 \%$ de solução de sacarose de 30-50\% foi obtida após tempo de residência de 1,73,0 h. Utilizando-se concentrações maiores de substrato sacarose entre $60-70 \%$ foi necessário maior tempo de residência, entre 4-5 h. Utilizando-se concentração de substrato de $40 \%$ foi obtido o maior rendimento em isomaltulose de $94 \%$, sendo obtidos menores rendimentos quando foram utilizadas concentrações abaixo de $40 \%$. A estabilidade operacional das colunas de leito empacotado foi de 155 dias, quando se consideraram taxas de conversão acima de $50 \%$. A quantidade de produto acumulado após o processo foi de $1488 \mathrm{~kg}$ de isomaltulose produzida por $\mathrm{dm}^{3}$ de biocatalisador.

\section{APLICAÇÕES DA ISOMALTULOSE}

Os carboidratos da dieta compreendem um complexo grupo de alimentos que possuem diversas propriedades fisiológicas e nutricionais ${ }^{77}$. A sacarose é o principal açúcar consumido no Brasil e tem a desvantagem de ser cariogênico. Bactérias da placa dentária, principalmente Streptococcus mutans, estão relacionadas com o desenvolvimento de cáries dentárias como microrganismos patogênicos primários em humanos e animais. Streptococcus mutans produz glicosiltransferase extracelular, que catalisa a síntese de glucana extracelular solúvel e insolúvel a partir de sacarose. A síntese de glucana promove a aderência de Streptococcus mutans às superfícies sólidas, incluindo aquelas dos dentes. Estes microrganismos são capazes de metabolizar mono e dissacarídeos produzindo ácidos, provocando a queda do $\mathrm{pH}$ da saliva e na interface placa-esmalte dos dentes favorecendo a desmineralização do esmalte e, conseqüentemente, desenvolvendo a cárie ${ }^{14,78}$.

$\mathrm{O}$ interesse na produção de isômeros da sacarose tem aumentado devido às similaridades sensoriais e ao menor potencial cariogênico. A sacarose possui cinco isômeros: trealulose, turanose, maltulose, leucrose e isomaltulose. A isomaltulose pode ser empregada na maioria dos alimentos industrializados como substituinte da sacarose sem qualquer alteração nos tradicionais processos de manufatura, sendo aplicada na confecção de produtos de panificação, caramelos, frutas enlatadas, gomas de mascar, produtos à base de chocolate, confeitos, pudins, recheios e coberturas, bebidas para esportistas e pasta de dente ${ }^{79}$.

\section{Cariogenicidade}

Estudos com isomaltulose, como substituto da sacarose, incluindo produção de ácidos em placa dentária in vivo e in vitro, produção de ácido em suspensão de material de placa dentária por Streptococcus mutans e efeito da isomaltulose na síntese de glucana têm sido realizados nas últimas décadas ${ }^{80,81}$.

Ooshima et al.${ }^{14}$ realizaram estudos relacionados à cárie dentária em ratos utilizando a isomaltulose. A atividade cariogênica foi examinada em experimentos in vitro e in vivo. Em meio contendo isomaltulose $1 \%(\mathrm{p} / \mathrm{v})$, Streptococcus mutans pertencentes aos sorotipos a, d e g não fermentaram o carboidrato; no entanto, os sorotipos b, c, e e f fermentaram. A isomaltulose inibiu significativamente a síntese de glucana insolúvel a partir da sacarose por Streptococcus mutans. Em experimentos in vivo, ratos foram infectados com Streptococcus mutans 6715 e alimentados com uma dieta contendo $56 \%$ de isomaltulose e não desenvolveram cáries significativas quando comparados aos grupos controles, os quais foram alimentados com sacarose, glicose, frutose ou glicose e frutose. Os autores comprovaram que a dieta em que se substituiu metade da sacarose por isomaltulose resultou em decréscimo no desenvolvimento de cáries.

Foi descrito o efeito de freqüentes enxágües com solução de isomaltulose e glicose na produção de ácido em placa dentária humana $^{82}$. Após 6 semanas e 6 enxágües diários com solução de isomaltulose $15 \%(\mathrm{p} / \mathrm{v})$ e glicose $15 \%(\mathrm{p} / \mathrm{v})$ foi observado que a isomaltulose provocou menor queda de $\mathrm{pH}($ de 7 a 6,2$)$ em relação à glicose, sendo a isomaltulose considerada menos acidogênica. Sasaki et al. ${ }^{83}$ compararam a cariogenicidade provocada por isomaltulose e sacarose em ratos infectados com Streptococcus mutans E-49. Três grupos de ratos Wistar foram alimentados com dietas contendo $56 \%$ de isomaltulose, outra contendo $56 \%$ de sacarose e uma outra composta de uma mistura de $17,5 \%$ sacarose e $38,5 \%$ isomaltulose. Os animais foram infectados com Streptococcus mutans E-49, sendo que metade dos animais foi mantida com a dieta por 8 semanas, e a outra metade, por 14 semanas. Somente cárie sulcal foi encontrada nos animais alimentados com isomaltulose. O grupo alimentado com sacarose apresentou lesões cáries buco-lingual, sulcal e superficial, enquanto que o grupo alimentado com a mistura de açúcares apresentou menos lesões buco-lingual em relação aos animais alimentados somente com sacarose.

Takazoe et $a l .{ }^{6}$ indicaram a isomaltulose como possível substituto da sacarose em alimentos devido a sua baixa cariogenicidade. Foram realizados estudos incluindo produção de ácido em placa dentária e efeito da isomaltulose na síntese de glucana por Streptococcus mutans. Testes em humanos demonstraram que, após enxágüe da boca com soluções de isomaltulose e sacarose 25,40 e $50 \%(\mathrm{p} / \mathrm{v})$, houve uma queda menor de $\mathrm{pH}$ naquelas pessoas que utilizaram isomaltulose. No estudo da determinação de produção de ácido em suspensões contendo placa dentária foi observado que a produção de ácido foi menor na presença de isomaltulose em relação à sacarose. Foi demonstrado que a produção de ácido foi muito baixa na presença de Streptococcus mutans E-49 em relação à sacarose e que nenhuma glucana insolúvel foi sintetizada a partir da isomaltulose pelo mesmo microrganismo.

Hamada $^{84}$ citou que cárie dentária é uma doença multifuncional provocada pela interação de três fatores: dentes, bactérias cariogênicas (principalmente Streptococcus mutans e Streptococcus sobrinus) e fermentação de açúcares. Inicialmente há a adesão das bactérias na superfície dos dentes, acompanhada pela síntese de glucana insolúvel em água a partir da sacarose por via enzimática pela ação de glicosiltransferases. Foi demonstrado que restrições de sacarose em dietas ou uso de substituintes não fermentáveis da sacarose influenciaram na atividade de glicosiltransferases resultando em diminuição das cáries. Isômeros da sacarose, como isomaltulose e trealulose, não são substratos para glicosiltransferases dos Streptococcus e não são utilizados como fonte de energia.

\section{Propriedades, nutrição e metabolismo da isomaltulose}

A isomaltulose possui ponto de fusão de $123-124^{\circ} \mathrm{C}$, menor que a sacarose $\left(190^{\circ} \mathrm{C}\right)$. Possui boa doçura e perfil similar ao da sacarose, não deixando sabor residual. A solubilidade é metade daquela da sacarose, em temperatura ambiente. A viscosidade é ligeiramente 
menor. Não é higroscópica como sacarose e lactose. Resiste à hidrólise ácida (ácido cítrico 1,5-15\%) e, desta forma, alimentos acidificados ou com vitamina $\mathrm{C}$ contendo isomaltulose são mais estáveis que aqueles contendo sacarose. Soluções de isomaltulose $20 \%$ a pH 2,0 em ebulição não sofreram hidrólise, após $1 \mathrm{~h}$. A termo-estabilidade é ligeiramente menor que a da sacarose $\mathrm{e}^{11,79}$. A estabilidade microbiana de produtos preparados com isomaltulose é muito boa. A concentração de insulina e frutose encontrada no plasma humano, após a ingestão da isomaltulose, é aproximadamente metade daquela encontrada após ingestão da sacarose. Em todas as quantidades testadas, as taxas de aumento dos níveis de glicose, insulina e frutose no sangue foram menores para isomaltulose que para sacarose. Como resultado da menor taxa de clivagem e conseqüentemente menor absorção dos monossacarídeos a partir da sacarose, nenhum aumento de desconforto intestinal foi observado. A isomaltulose é completamente absorvida, embora mais lentamente que a sacarose.

Kawai et al. ${ }^{85}$ investigaram e compararam a concentração de glicose e insulina no plasma em resposta à ingestão de isomaltulose e sacarose. O nível de glicose no plasma aumentou gradualmente e atingiu um máximo de 110,9 mg/dL após $60 \mathrm{~min}$, quando se administraram $50 \mathrm{~g}$ de isomaltulose, permanecendo no mesmo nível após 120 min. Ao se administrar em $50 \mathrm{~g}$ de sacarose, o mesmo grupo de voluntários apresentou um nível máximo de glicose no plasma de 143,3 mg/dL após $30 \mathrm{~min}$, com acentuada queda posterior. $\mathrm{O}$ aumento acumulativo de glicose no plasma devido à isomaltulose foi menor quando comparada à sacarose e as alterações dos níveis da insulina no plasma acompanharam paralelamente os níveis de glicose. Os resultados demonstraram que a isomaltulose é absorvida mais lentamente que a sacarose, sendo indicada como adoçante para pacientes diabéticos. Posteriormente foi demonstrado em experimentos in vitro, com mucosa intestinal humana, que o valor da digestão da isomaltulose foi cinco vezes menor quando comparado com a da sacarose ${ }^{86}$. Em estudos in vivo foi demonstrado que a administração oral de isomaltulose $(1 \mathrm{~g} / \mathrm{kg})$ provocou um leve aumento na glicose e insulina do plasma. Os resultados sugeriram que a isomaltulose pode ser utilizada como adoçante calórico por pacientes diabéticos devido ao baixo índice glicêmico ${ }^{86}$.

Os efeitos teratogênicos e mutagênicos foram avaliados em fetos de ratos Wistar alimentados com dietas contendo diferentes níveis de isomaltulose ( 0 a $10 \%$ ), do primeiro ao vigésimo primeiro dia de gestação ${ }^{87}$. Não foram encontrados indícios tóxicos, nenhum efeito na atuação reprodutiva, em análises dos embriões, fetos, vísceras e esqueletos. A dieta contendo $10 \%$ de isomaltulose seria equivalente ao consumo de aproximadamente $7 \mathrm{~g} / \mathrm{kg}$ de peso corpóreo/dia. O potencial toxicológico da isomaltulose também foi estudado, administrando-se dietas de 0 a $10 \%$ por 13 semanas em grupos de ratos Wistar ${ }^{88}$. Observações clínicas diárias evidenciaram que peso corporal, eficiência na conversão dos alimentos e consumo de alimentos e água não foram afetados em nenhuma etapa do estudo. Exames oftalmológico, sanguíneo, de urina, dos tecidos, do sistema nervoso, da atividade motora e imunotoxicidade não revelaram nenhuma anormalidade devido à ingestão de isomaltulose. Foi concluído que a administração de isomaltulose na dieta até $10 \%$, por 13 semanas, pode ser tolerado sem qualquer sinal de toxicidade.

Lina et al ${ }^{89}$ relataram que a isomaltulose é um dissacarídeo de ocorrência natural, comercialmente produzida pela conversão enzimática a partir da sacarose e tem sido utilizada como um adoçante no Japão desde 1985. A isomaltulose é utilizada como um substituto não cariogênico da sacarose em produtos para diabéticos e pré-diabéticos. Estudos in vivo com ratos e porcos indicaram que a isomaltulose é completamente hidrolisada e absorvida no intestino delgado. Foi demonstrado em estudos in vitro que diversas enzimas intestinais (incluindo humanas) podem hidrolisar isomaltulose. A taxa de hidrólise, no entanto, é muito baixa quando comparada com a da sacarose e maltose. Logo, os níveis de glicose e insulina no plasma sanguíneo em humanos, após administração oral, aumentou lentamente e atingiu menor valor máximo em relação à administração da sacarose. Após absorção, frutose e glicose foram metabolizados normalmente. A administração de altas doses (de 7 e $8,1 \mathrm{~g} / \mathrm{kg}$ de massa corpórea/dia em ratos machos e fêmeas, respectivamente) de isomaltulose não resultou em efeitos adversos. Isomaltulose não induziu toxicidade embrionária, efeitos mutagênicos ou efeitos teratogênicos em ratas grávidas e nenhum material tóxico nos fetos foi observado. Em estudos com pessoas saudáveis e diabéticas, altas doses acima de $50 \mathrm{~g}$ foram toleradas sem sinais de desconforto intestinal. Com bases nestes resultados conclui-se que o uso de isomaltulose como um adoçante alternativo é tão seguro quanto outros açúcares digeríveis contendo glicose e frutose.

\section{Produção de isomalte a partir de isomaltulose}

O isomalte também conhecido como Isomalt ${ }^{\circledR}$, Palatinit ${ }^{\circledR}$, palatinitol ou isomaltitol é uma mistura equimolar de [6- $O-(\alpha-\mathrm{D}-$ glicopiranosil)-D-sorbitol] e [1-O-( $\alpha$-D-glicopiranosil)-D-manitol] e é produzido por hidrogenação da isomaltulose ${ }^{79,90-94}$ (Esquema 2). A doçura relativa do isomalte é cerca de $50 \%$ da sacarose e apresenta sabor agradável similar ao da sacarose. Ndindayino et $a l .{ }^{95}$ relataram que há um grande interesse em adoçantes alternativos, como mono e dissacarídeos álcoois, também chamados polióis, em formulações farmacêuticas. A razão deste interesse é a combinação do sabor natural adocicado, conteúdo calórico reduzido e características não cariogênicas. A maioria dos polióis pode ser consumida por diabéticos sem qualquer aumento significativo da glicose, insulina ou concentração de ácido lático. Dentre os polióis, o isomalte é um açúcar-álcool derivado da sacarose. Na primeira etapa de obtenção, a sacarose é convertida em isomaltulose pela transglicosilação enzimática. Este novo açúcar é considerado mais resistente a ácidos e à ação microbiana, pois a ligação $\alpha-1,6$ entre glicose e frutose é mais estável que a ligação $\alpha, \beta-1,2$ da sacarose. No segundo passo do processo, o isomalte é obtido pela hidrogenação da isomaltulose em solução aquosa neutra. Além das vantagens técnicas em comparação a outros polióis, o isomalte tem a vantagem de ser similar à sacarose, muito menos higroscópico e com melhores propriedades sensoriais ${ }^{96}$.
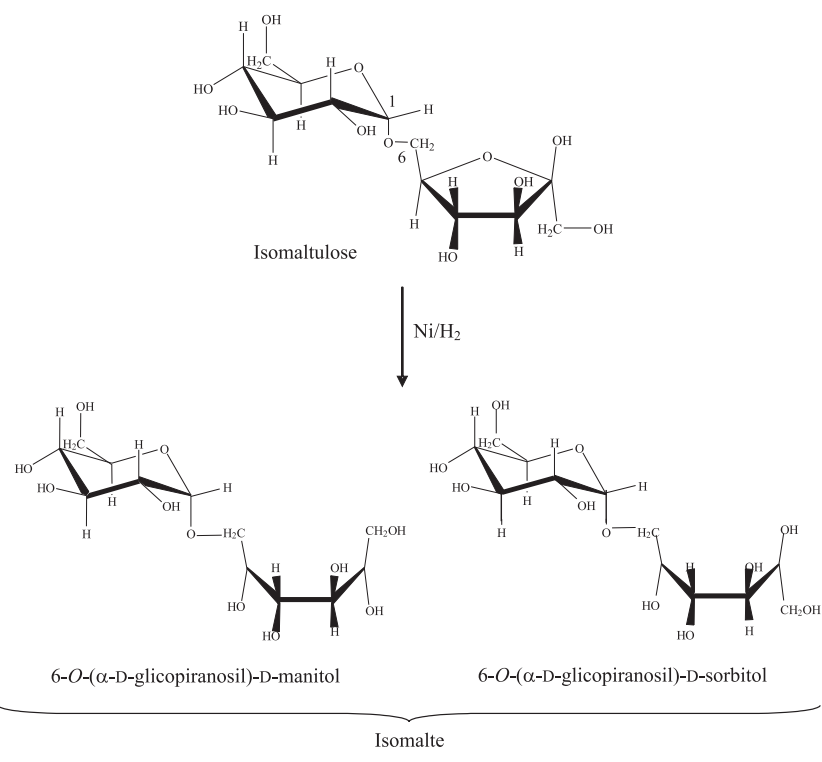

Esquema 2. Conversão de isomaltulose em isomalte por hidrogenação 
Em 1985, estimou-se que a produção de isomalte seria de aproximadamente 20.000-25.000 t/ano e o preço estimado em US\$3/kg. $\mathrm{O}$ consumo de isomalte na Europa correspondia a aproximadamente 15.000 t/ano, nos Estados Unidos a 2.000-3.000 t/ano e na América do Sul a $2.000 \mathrm{t} / \mathrm{ano}^{97}$. O isomalte pode ser obtido na forma cristalina, não é redutor e, ao contrário da sacarose, é extremamente estável à hidrólise enzimática. Também não pode ser fermentado por grande número de leveduras e microrganismos ${ }^{96,98}$. $\mathrm{O}$ isomalte não deixa sabor residual e tem sido utilizado como açúcar dietético em produtos de confeitaria, gomas de mascar, bebidas carbonatadas e sobremesas $^{81}$. $\mathrm{O}$ isomalte não é higroscópico e o ponto de fusão é de cerca de $145-150{ }^{\circ} \mathrm{C}$ e não sofre reação de Maillard ${ }^{97-99}$. O isomalte pode ser facilmente triturado para serem obtidos grânulos de $100 \mu \mathrm{m}$, propriedade que é importante para a fabricação de chocolates e gomas de mascar. $\mathrm{O}$ pó finamente granulado pode ser seco para uso como adoçante e pode ser moldado em tabletes ${ }^{100}$. O isomalte reforça a transferência de sabor aos alimentos e um efeito sinergístico ocorre quando é combinado com outros açúcares álcoois como xilitol, sorbitol, manitol (10\%). O mesmo sinergismo é obtido quando é combinado com outros adoçantes de doçura intensa como acesulfame$\mathrm{K}$, aspartame, ciclamato e sacarina. A adição de isomalte tende a mascarar o sabor amargo metálico residual desses adoçantes. O isomalte não tem efeito refrescante como outros açúcares álcoois ${ }^{88}$.

\section{CONCLUSÕES}

A isomaltulose, um isômero da sacarose, é um açúcar redutor composto de uma molécula de glicose e de frutose unidas por uma ligação glicosídica $\alpha-1,6$, encontrada naturalmente no mel e no caldo de cana-de-açúcar em pequenas quantidades. A isomaltulose, também conhecida como Palatinose ${ }^{\circledR}$, possui um sabor adocicado suave e propriedades físicas e sensoriais muito similares às da sacarose. Devido ao seu baixo potencial cariogênico é utilizada como ingrediente e substituinte da sacarose em diversos produtos. A partir da isomaltulose podem ser obtidos diversos compostos de interesse industrial, sendo o mais utilizado o isomalte, um açúcar álcool obtido por hidrogenação, que possui baixo valor calórico e baixa cariogenicidade, utilizado em produtos dietéticos e em formulações farmacêuticas. O meio mais utilizado para a conversão de sacarose em isomaltulose é através da glicosiltransferase produzida por algumas linhagens bacterianas. O sistema de células imobilizadas utilizando alginato de cálcio é o método mais utilizado para a produção de isomaltulose, pois permite o seu uso contínuo, previne contaminações de produtos com as células, as mantém igualmente distribuídas no reator, estabilizando assim o processo de biocatálise. Diversos estudos toxicológicos em animais e clínicos em seres humanos têm demonstrado a segurança da utilização da isomaltulose sendo, portanto, um potencial substituinte da sacarose como ingrediente em alimentos e em formulações farmacêuticas.

\section{AGRADECIMENTOS}

À Coordenação de Aperfeiçoamento de Pessoal de Nível Superior (CAPES) e à FINEP (Financiadora de Estudos e Projetos em Pesquisa) pelo apoio financeiro.

\section{REFERÊNCIAS}

1. http://www.conab.gov.br/download/safra/Primeiro_Levantamento_Cana_200607_maio06.pdf, acessada em Agosto 2006.

2. Siddiqui, I. R.; Furgala, B.; J. Apicult. Res. 1967, 6, 139.

3. Krastanov, A.; Yoshida, A.; J. Ind. Microbiol. Biotechnol. 2003, 30, 593.

4. Nakakuki, T.; Pure Appl. Chem. 2002, 74, 1245.
5. Shimizu, J.; Suzuki, K.; Nakajima, Y.; GB pat. 2,082,591 1982.

6. Takazoe, I.; Frostell, G.; Ohta, K.; Topitsoglou, V.; E Sasaki, N.; Sweden Dent. J. 1985a, 9, 81 .

7. Hashimoto, H.; Yamada, K.; Yoshimura, J.; Biotechnol. Lett. 1987, 12, 849.

8. Godshall, M. A.; Food Technol. 1997, 51, 63.

9. Huang, J. H.; Hsu, L. H.; Su, Y. C.; J. Ind. Microbiol. Biotechnol. 1998, 21,22 .

10. Cheetham, P. S. J.; Imber, C. E. E; Isherwood, J.; Nature 1982, 299, 628.

11. Takazoe, I. Em Progress in Sweeteners; Grenby, T. H., ed.; Elsevier Applied Science: New York, 1989, cap. 6.

12. Lichtenthaler, F. W.; Peters, S.; C. R. Chim. 2004, 7, 65.

13. Maki, Y.; Ohta, K.; Takazoe, Y.; Matsukubo, Y.; Takaesu, Y.; Topitsoglou, V.; Frostell, G.; Caries Res. 1983, 17, 335.

14. Ooshima, T.; Izumitani, A.; Sobue, S.; Okahashi, N.; Hamada, S.; Infect. Immun. 1983, 39, 43.

15. Irwin, W. E.; Food Technol. 1990, 44, 128

16. Lichtenthaler, F. W.; Mondel, S.; Pure Appl. Chem. 1997, 89, 1853.

17. Kashimura, J.; Kimura, M. E.; Itokawa, Y.; J. Nutr. Sci. Vitaminol. 1996, $42,69$.

18. Tsuyuki, K.; Sugitani, Y.; Miyata, Y.; Ebashi, T.; Nakajima, Y. J.; J. Gen. Appl. Microbiol. 1992, 38, 483.

19. Kakinuma, H.; Yuasa, H.; Hashimoto, H.; Carbohydr. Res. 1998, 312, 103.

20. Sarkki, M. L.; Heikkila, H.; Viljava, T.; US pat. 5,939,294 1999.

21. Lund, B. M.; Wyatt, G. M.; J. Gen. Appl. Microbiol. 1973, 78, 330.

22. Kawaguti, H. Y.; Manrich, E.; Sato, H. H.; Braz. J. Microbiol. 2005, 36, 227.

23. Kawaguti, H. Y.; Manrich, E.; Sato, H. H.; Biochem. Eng. J. 2006a, 29, 270.

24. Kawaguti, H. Y.; Buzzato, M. F.; Orsi, D. C. Suzuki, G. T.; Sato, H. H.; Process Biochem. 2006b, 41, 2035.

25. Cheetham, P. S. J.; Garrett, C.; Clark, J.; Biotechnol. Bioeng. 1985, $27,471$.

26. Mcallister, M.; Kelly, C. T.; Doyle, E.; Fogarty, W. M.; Biotechnol. Lett. 1990, 12,667 .

27. Véronèse, T.; Perlot, P.; Enzyme Microb. Technol. 1999, 24, 263.

28. Park, Y. K.; Uekane, R. T.; Pupin, A. M.; Biotechnol. Lett. 1992, 14, 547.

29. Park, Y. K.; Uekane, R. T.; Sato, H. H.; Rev. Microbiol. 1996, 27, 131.

30. Moraes, A. L. L.; Steckelberg, C.; Sato, H. H.; Pinheiro, A.; Ci. Tecnol. Aliment. 2005, 25, 95.

31. Schiweck, H.; Steinle, G.; Muller, L.; Gau, W.; Munir, M.; US pat. 4,233,439 1980

32. Heikkila, H.; Sarkki, M.; Lindroos, M.; Ojala, P.; Ravanko, V.; Tylli, M.; US pat. 6,146,856 2000.

33. Kawaguti, H. Y.; Sato, H. H.; Elect. J. Biotec. 2006, 9, 482

34. Lantero, O. J.; US pat. 8,210,9404.2 1983.

35. Bucke, C.; Cheetham, P. S. J.; US pat. 4,670,387, 21987.

36. Ahn, S. J.; Yoo, J. H.; Lee, H. C.; Kim, S. Y.; Noh, B. S.; Kim, J. H.; Lee, J. K.; Biotechnol. Lett. 2003, 25, 1179.

37. Weidenhageen, R.; Lorenz, S.; Zeitschrift für die Zuckerindustrie 1957, 82, 533.

38. Nagai-Miyata, Y.; Tsuyuki, K.; Sugitani, T.; Ebashi, T.; Nakajima, Y.; Biosci. Biotechnol. Biochem. 1993, 57, 2049.

39. Cheetham, P. S. J.; Biochem. J. 1984, 220, 213.

40. Mundra, P.; Desai, K.; Lele, S.; Bioresour. Technol., 2007, 98, 289.

41. Kawaguti, H. Y.; Buzzato, M. F.; Sato, H. H.; J. Ind. Microbiol. Biotechnol. 2004, 34, 261.

42. Li, X.; Zhao, C.; Na, Q.; Zhang, D. J.; Appl. Microbiol. 2003, 95, 521.

43. Wu, L.; Birch, R. G.; J. Appl. Microbiol. 2004, 97, 93.

44. Miyata, Y.; Sugitani, T.; Tsuyuki, K.; Ebashi, T.; Nakajima, Y.; Biosci. Biotechnol. Biochem. 1992, 56, 1680.

45. Krastanov, A.; Blazheva, D.; Yanakieva, I.; Kratchanova, M.; Enzyme Microb. Technol. 2006, 39, 1306.

46. Celestino, E. M.; Dissertação de Mestrado, Universidade Estadual de Campinas, Brasil, 1998.

47. Nagai, Y.; Sugitani, T.; Tsuyuki, K.-I.; Biosci. Biotechnol. Biochem. 1994 $58,1789$.

48. Wu, L.; Birch, R. G.; Appl. Environ. Microbiol. 2005, 71, 1581.

49. Véronèse, T.; Perlot, P.; FEBS Lett. 1998, 441, 348.

50. Chibata, I.; Tosa, T.; Sato, T.; Appl. Microbiol. 1974, 27, 878.

51. Walsh, P. K.; Malone, D. M.; Biotechnol. Adv. 1995, 13, 13.

52. Guy-Alain, J.; Jouenne, T.; Biotechnol. Adv. 2004, 22, 633.

53. Scott, C. D.; Enzyme Microb. Technol. 1987, 9, 66.

54. Karel, S. F.; Libicki, S. B.; Robertson, C. R.; Chem. Eng. Sci. 1985, 40, 1321.

55. Park, J. K.; Chang, H. N.; Biotechnol. Adv. 2000, 18, 303.

56. Kourkoutas, Y.; Bekatorou, A.; Banat, I. M.; Marchant, R.; Koutinas, A. A.; Food Microbiol. 2004, 21, 377.

57. Veberlen, P. J.; De Schutter, D. P.; Delvaux, F.; Verstrepen, K. J.; Delvau, F. R.; Biotechnol. Lett. 2006, 25, 1515.

58. Lacroix, C.; Doleyres, Y.; Int. Diary J. 2005, 15, 973.

59. Verbelen, P. J.; Verstrepen, K. J.; Delvaux, F. R.; Biotechnol Lett. 2006, 28,1515 . 
60. Jen, A. C.; Wake, M. C.; Mikos, A. G.; Biotechnol. Bioeng. 1996, 50, 357.

61. Willaert, R. G. Em Fermentation Microbiology and Biotechnology; ElMansi, E. M. T.; Bryce, C. F. A., eds.; Taylor \& Francis: London, 2006, cap. 10.

62. Jin, Y. L.; Speers, R. A.; Food Res. Int. 1998, 31, 421

63. Lebeau, T.; Jouenne, T.; Junter, G-A.; Enzyme Microb. Technol. 1998, 22, 434.

64. Chan, L. W.; Lee, H. Y.; Heng, P. W. S.; Int. J. Pharm. 2002, 242, 259.

65. Vorlop, K. D.; Klein, J. Em Enzyme Technology; Lafferty, R. M., ed; Springer Berlin Heidelberg: New York, 1983, p. 219.

66. Ogbonna, J. C.; Amano, Y.; Nakamura, K.; J. Ferment. Bioeng. 1989, 67, 92.

67. Hulst, A. C.; Tramper, J.; Enzyme Microb. Technol. 1989, 11, 546.

68. Konsoula, Z.; Liakopoulou-Kyriakides, M.; Process Biochem. 2006, 41, 343.

69. Konsoula, Z.; Liakopoulou-Kyriakides, M.; Enzyme Microb. Technol. 2006 $39,690$.

70. Guo, X. L.; Deng, G., Xu J.; Wang, M. X.; Enzyme Microb. Technol. 2006, $9,1$.

71. Idris, A.; Wahidin, S.; Process Biochem. 2006, 41, 1117.

72. Klein, J.; Stock, J.; Vorlop, K. D.; Appl. Microbiol. Biotechnol. 1983, 18, 86.

73. Ertesvag, H.; Valla, S.; Polym. Degrad. Stab. 1998, 59, 85.

74. Chan, L. W.; Lee, H. Y.; Heng, P. W. S.; Int. J. Pharm. 2002, 242, 259

75. Bahulekar, R.; Ayyangar, N. R.; Ponrathnam, S.; Enzyme Microb. Technol. 1991, 13, 858.

76. Moraes, A. L. L.; Tese de Doutorado, Universidade Estadual de Campinas, Brasil, 2002.

77. Loo, J. V.; Cummings, J.; Delzenne, N.; Englyst, H.; Franck, A.; Hopkins, M.; Kok, N.; Macfarlane, G.; Newton, D.; Quigley, M.; Roberfroid, M.; Vliet, T. V.; Heuvel, E. V. D.; Br. J. Nutr. 1999, 81, 121.

78. Moynihan, P. J.; J. Dent. 1998, 26, 209.

79. Irwin,W. E.; Sträter, P. J. Em Alternative Sweeteners; Nabors, L. O.; Gelardi, R. C., eds.; Marcel Dekker: New York, 1991, cap. 16.

80. Takazoe, I.; Int. Dent. J. 1985, 35, 58.

81. Takazoe, I.; Otha, K.; Shimizu, J.; Suzuki, K.; Iwakura, T.; Nakajima, Y;
US pat. 4,556,429 $\mathbf{1 9 8 5 b}$.

82. Topitsoglou, V.; Sasaki, N.; Frostell, G.; Caries Res. 1984, 18, 47.

83. Sasaki, N.; Topitsoglou, V.; Takazoe, I.; Frostell, G.; Sweden Dent. J. 1985, 9,149 .

84. Hamada, S.; Pure Appl. Chem. 2002, 74, 1293.

85. Kawai, K.; Okuda, Y.; Yamashita, K.; Endocrinology Japonica 1985, 32, 933.

86. Kawai, K.; Yoshikawa, H.; Murayama, Y.; Okuda, Y.; Yamashita, K.; Horm. Metab. Res. 1989, 21, 338

87. Lina, B. A. R.; Smits-Van Prooije, A. E. E.; Waalkens-Berendsen, D. H.; Food Chem. Toxicol. 1997, 35, 309.

88. Jonker, D.; Lina, B. A. R.; Kozianowski, G.; Food Chem. Toxicol. 2002, 40,1383 .

89. Lina, B. A. R.; Jonker, D.; Kozianowski, G.; Food Chem. Toxicol. 2002, $40,1375$.

90. Snodin, D. J.; Daniel, J. W. Em Developments in Sweeteners 2; Grenby, T. H.; Parker, K. J.; Lindley, M. G., eds.; Elsevier Applied Science: New York, 1983, cap. 16.

91. Goldscher, R. L.; US pat. 5,679,78121 1997.

92. Degelmann, H.; Kowalczyk, J.; Kunz, M.; Schuttnhelm, M.; US pat. 103,894,15 2000.

93. Duflot, P.; Fouache, C.; US pat. 6,204,378, 202001.

94. Havenaar, R. Em Developments in Sweeteners 3; Greenby, T. H., ed., Elsevier- Applied Science Publishers: London, 1987, cap. 7.

95. Ndindayino, F.; Henrist, D.; Kiekens, F.; Vervaet, C.; Remon, J. P.; Int. J. Pharm. 1999, 189, 113.

96. Ziesenitz, S. C. Em Advances in Sweeteners; Grenby, T. H., ed.; Blackie Academic \& Professional: Glasgow, 1996, cap. 6.

97. Sträter, P. J. Em Alternative Sweeteners; Nabors, L. O.; Gekardi, R. C., eds.; Marcel Dekker: New York, 1985, cap. 11.

98. Linke, H. A. B. Em ref. 94, cap. 6.

99. Schiweck, H. M.; Willibald-Ettle, I. Em ref. 96, cap. 4.

100. Grenby, T. H. Em ref. 90, cap. 3. 